\title{
Conferencia Dr. Hernán Alessandri R. 2011. Historia del Cáncer Pulmonar: otro monstruo creado por el hombre
}

\author{
ALVARO UNDURRAGA P.*
}

Hernán Alessandri lecture 2011.

History of lung cancer: another monster created by mankind

In Profesor Alessandri's days lung cancer cases in Chile and all over the world were very few. In German medical papers in the third decade of $X X^{\text {th }}$ century some relationship between lung cancer and smoking habits was reported but only in the middle of the century medical literature reported evidences about this relationship. Smoking habit become universal in the $X X^{\text {th }}$ century. Medical community and public opinion were formally informed about the danger of smoking, for the first time in USA, in 1964 in the first Report of General Surgeon. Nowadays lung cancer is the cause of death of 2,500 Chileans a year and over one million all over the world. Thoracic $X$ rays and rigid bronchoscopy were for long time the only diagnostic methods in lung cancer. Today we have a lot of sophisticated tools that are mentioned in this paper. Surgery was and continues being the principal therapeutic weapon against the disease. The first surgical intervention performed was a pneumonectomy whose history is related in this review. Several other therapies are available in our days for the disease. A section of this paper is reserved to analyse patients and the disease. A very touching testimony of a poet written when he suffered from the disease is quoted in the text. The paper finishes with a light of hope based on the new immunological and molecular methods for treatment and the radiological approaches for early diagnosis that are available today.

Key words: History of medicine, lung cancer, tobacco, general surgeon report, bronchoscopy, surgery, pneumonectomy, thoracic CT scan.

\section{Resumen}

En los tiempos del Prof. Alessandri los casos de cáncer pulmonar eran muy pocos en Chile y en el resto del mundo. La literatura médica alemana de la tercera década del siglo XX, observó cierta relación entre el hábito tabáquico y el cáncer pulmonar, pero sólo 20 años después la literatura médica evidenció esta relación. El hábito tabáquico se hizo universal en el siglo XX. La comunidad médica y el público general fueron advertidos por primera vez del peligro del tabaquismo en 1964 en el primer informe para el Cirujano General de EE.UU. Hoy día mueren al año 2.500 chilenos y 1 millón de personas en el mundo por la enfermedad. La radiografía de tórax y la broncoscopía rígida fueron por largo tiempo los únicos métodos diagnósticos en cáncer pulmonar. Hoy tenemos muchos métodos diagnósticos sofisticados que se revisan en este artículo. La cirugía era y continúa siendo la principal arma terapéutica contra la enfermedad. La primera intervención quirúrgica fue la neumonectomía cuya historia es relatada en esta publicación. Hoy día tenemos muchas otras armas terapéuticas disponibles. En el artículo se reserva una sección para analizar los pacientes y la enfermedad. Se cita un conmovedor testimonio de un poeta que lo escribió mientras sufría de la enfermedad. El artículo termina con una luz de esperanza en relación a nuevos métodos inmunológicos y moleculares de diagnóstico y radiológicos de diagnóstico precoz, disponibles hoy en día.

Palabras clave: Historia de la medicina, cáncer pulmonar, tabaquismo, informe del cirujano general, broncoscopía, cirugía pulmonar, neumonectomía, TAC torácico.

* Servicio Médico-Quirúrgico, Instituto Nacional del Tórax. Santiago. Chile. 


\section{Introducción}

En la conferencia Hernán Alessandri del año 2007, el Dr. Humberto Reyes afirmaba: Entre 1930 y 1960 la medicina alcanzó en Chile un nivel de excelencia ejemplar en el ámbito latinoamericano. Este progreso ocurrió en un país geográficamente alejado de los grandes centros en que se generaba el progreso. En esas décadas el nivel de la medicina en Chile se aproximó más que nunca antes al que tenían los países desarrollados. Para que esto ocurriera fue crucial el que existieron individuos inteligentes, visionarios, tenaces y amantes de su profesión. Una de las personalidades más destacadas de esa época fue don Hernán Alessandri Rodríguez.

El Profesor Hernán Alessandri fue nombrado profesor titular de Medicina y jefe de Servicio de Medicina del Hospital del Salvador en 1944. En 1960, a los 58 años fue elegido Decano de la Facultad de Medicina de la Universidad de Chile.

\section{El cáncer pulmonar en la época del Dr. Alessandri}

El cáncer pulmonar era una enfermedad muy infrecuente y es posible que en las memorables reuniones que presidía el Profesor Alessandri muy rara vez se discutiera un caso de cáncer pulmonar.

En ese tiempo, cuando se presentaba esa rara enfermedad se disponía de muy pocos recursos diagnósticos. Seguramente el recurso fundamental era el llamado "arte médico" el cual el profesor Alessandri dominaba.

El doctor Alejandro Goic en su semblanza del Profesor Alessandri nos relataba:

Asombraba su habilidad en el diagnóstico clínico, en una época en que los recursos auxiliares eran mucho más escasos e imprecisos que hoy. Su talento diagnóstico brotaba de su capacidad de observación, de sus conocimientos y habilidades semiológicas y de su amplio dominio de la patología ,todo lo cual procesaba magistralmente su inteligencia privilegiada.

Fuera de ese "arte médico" apenas se disponía de la radiología de tórax, con una calidad que hoy nos parece primaria, y la broncoscopía rígida con todas sus limitaciones para el diagnóstico y como recurso terapéutico de la cirugía. Muy posiblemente la mayoría de esos escasos enfermos de cáncer pulmonar, recibía otra acción médica que el Profesor Alessandri también dominaba y que nos la relata Alejandro Goic:

"Con gran sabiduría y sentido humanitario, cuando la medicina ya no tenía más que ofrecer a un paciente desahuciado, afirmaba: «hay momentos en que la ciencia debe dar paso a la caridad».

Otro gran clínico de esa época, el profesor español don Carlos Jiménez Díaz publicó por esos años una gran obra de clínica médica titulada "Lecciones de Patología Médica".

El tomo dedicado a enfermedades respiratorias, que dedica 250 páginas a la tuberculosis, sólo reserva unas pocas líneas al cáncer pulmonar y presenta una radiografía de tórax, con la técnica de esa época, y es interesante el comentario que la acompaña (Figura 1).

En la radiografía nos encontramos en la parte central y posterior del pulmón izquierdo una tumoración redondeada que no había lugar a esperar, porque el enfermo no se había quejado absolutamente ni de tos, ni de dolores de pecho, ni de fatiga. La tumoración es aproximadamente del tamaño de una mandarina y se encuentra situada a nivel del lóbulo superior izquierdo. El resto del pulmón aparece normal y las cúpulas diafragmáticas también. ¿Qué puede ser una tumoración redondeada, como esta, que nos encontramos en el pulmón en esta radiografía? Si fueran más deflecados sus contornos cabría la posibilidad de pensar en una infiltración tuberculosa del pulmón, y si a pesar de estar bien de-

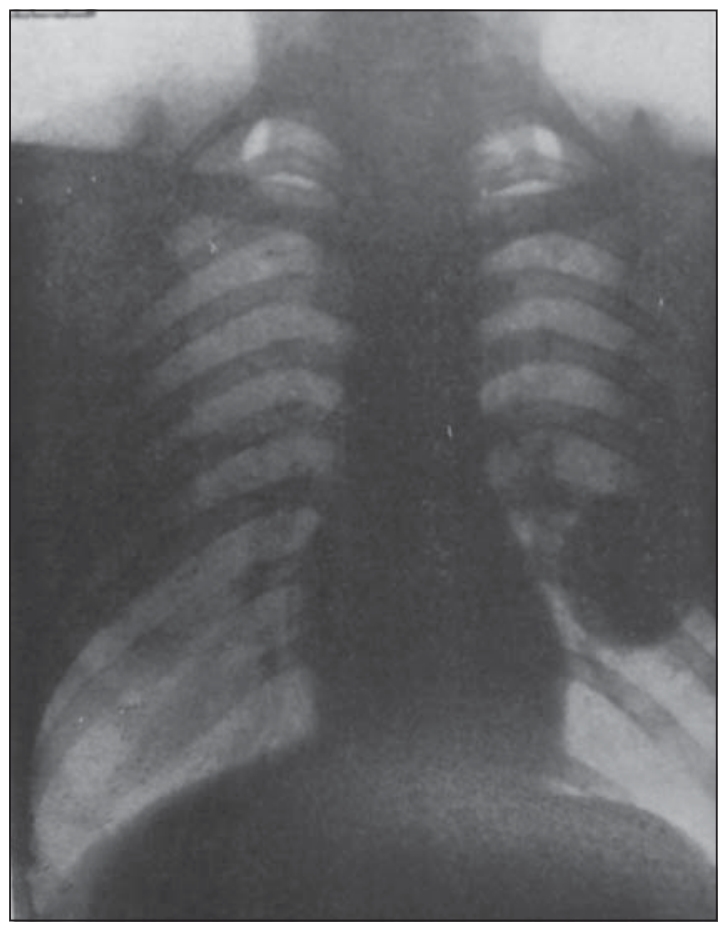

Figura 1. Caso clínico: Radiografía de tórax (detalles en el texto). 
limitada fuera pequeña podríamos pensar en ese proceso tuberculoso, que ya hemos estudiado en su día del infiltrado redondo; pero este infiltrado redondo bien delimitado es siempre múltiple, y aunque algunas veces llega a ser tan grande, como una pera chica o algo más, nunca alcanza un tamaño como el que acabamos de ver. De modo que estas cosas quedan exceptuadas por el simple examen de la radiografía. Pero caben otras posibilidades: podemos pensar en un tumor del pulmón de alguna de las numerosas clases de tumor pulmonar que pueden existir; es decir podemos pensar en un cáncer de pulmón, en un sarcoma, en una linfogranulomatosis, etc".

Esta es toda la referencia que en esa obra monumental se hace del cáncer pulmonar, lo que ilustra la rareza del cáncer pulmonar en aquella época.

\section{La rareza del cáncer pulmonar a comienzos y mediados del siglo XX}

En realidad antes de 1900 el cáncer pulmonar fue considerado como una "curiosidad médica". Adler en 1912 recopiló 374 casos de toda la literatura mundial en su libro "Primary Malignant Growth of the Lung and Bronchi: a Pathological and Clinical Study".

Esta enfermedad era casi inexistente a comienzos del siglo XX. En 1878 los tumores malignos del pulmón representaban sólo el 1\% de todos los cánceres en autopsia en el Instituto de Patología de la Universidad de Dresden, Alemania. Hacia 1918 el porcentaje había subido a casi el 10\% y en 1927 al 14\%. En la edición de 1930 del famoso Springer Handbook of Special Pathology se enfatiza que los tumores malignos del pulmón habían comenzado a aumentar especialmente después de la primera guerra mundial, la sobrevida desde el comienzo de la enfermedad a la muerte era de 0,5 a 2 años y que prácticamente todos los casos tenían historia previa de bronquitis crónica. Sobre las causas de ese sorpresivo avance de la enfermedad se especula sobre el posible papel de la polución atmosférica por gases y polvos causados por la industria, la responsabilidad del asfaltado de las calles, la exposición al gas en la $1^{\text {a }}$ guerra mundial, la pandemia de influenza de 1918, el trabajo con benceno y gasolina y en sólo una o dos frases se menciona brevemente el tabaquismo y se agrega que varias investigaciones fracasaron en mostrar tal asociación.

El famoso cirujano Alton Oshsner relataba que su curso fue convocado a ver una autopsia de un paciente de cáncer pulmonar y su docente les advirtió que posiblemente no verían otro caso igual en toda su vida de médicos. Diecisiete años después Oshsner recién vio un segundo caso. En 1936 él publicó junto al famoso cirujano cardíaco Michael DeBakey un notable artículo en el cual conjeturaron que el aumento del tabaquismo con la costumbre universal de inhalar el humo era probablemente un factor responsable, ya que el humo inhalado repetido constantemente por un largo período era una fuente de irritación crónica de la mucosa bronquial. Esta afirmación fue muy discutida y también ridiculizada por sus colegas incluso el gran cirujano Evarts A. Graham, llegó a afirmar: "Sí, hay un paralelismo entre la venta de cigarrillos y la incidencia del cáncer pulmonar, pero también hay un paralelismo entre la venta de calcetines de nylon y la incidencia de cáncer pulmonar...".

\section{Cáncer pulmonar y tabaquismo}

Ya en 1929 el médico alemán Fritz Lickint publicó que el cáncer pulmonar era especialmente frecuente en fumadores e incluso intentó iniciar en esa época una cruzada contra el tabaquismo en Alemania.

A pesar de ello las publicaciones sobre cigarrillo y cáncer pulmonar empezaron a aparecer sólo dos décadas más tarde. En un estudio caso-control publicado por Müller en 1940 en Alemania, categóricamente se expresa que el extraordinario aumento en el uso del tabaco es la causa más importante en la incidencia creciente del cáncer pulmonar. En esa época el cáncer pulmonar en Alemania era la segunda causa en frecuencia de muerte por cáncer, detrás del cáncer de estómago.

En 1943 el Instituto Alemán para Investigaciones sobre Consecuencias del Tabaco, comunicó un estudio en 109 casos de cáncer pulmonar en el cual sólo 3 eran no fumadores proporción muy diferente a lo encontrado en el grupo control. Sólo 10 años más tarde Doll y Hill en Inglaterra y Cuyler Hammond y Ernest Wynder en EE.UU. proporcionaron mayores evidencias sobre la asociación causal entre hábito tabáquico y cáncer pulmonar.

Sin embargo, los fumadores, incluyendo médicos, no querían, no podían imaginar o se rehusaban a creer que el hábito fuera deletéreo para la salud.

Cuando los europeos descubrieron América, los indígenas americanos de Las Antillas, La Florida, México y Brasil, hacían uso del tabaco desde tiempo inmemorial (Figura 2).

Sus adivinos y sacerdotes aspiraban el humo 


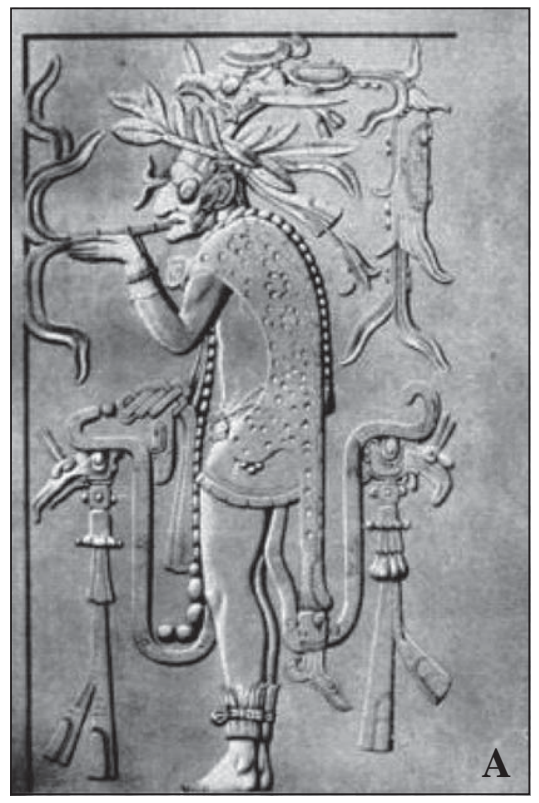

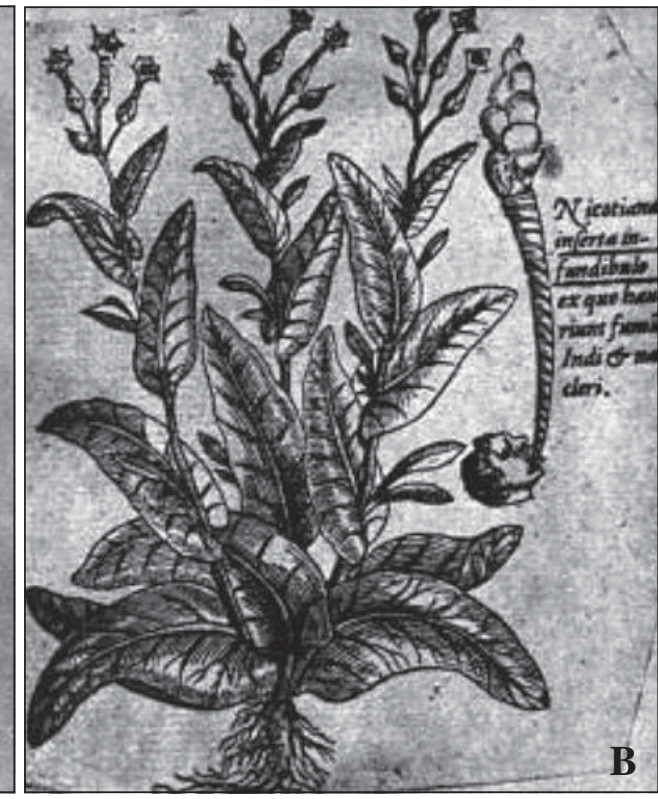

Figura 2. A: Un sacerdote maya fumando. Templo de Palenque, México. B: La primera representación de la planta de tabaco en Occidente, 1570. por la boca, con auxilio de un largo tubo, para pronosticar los resultados de alguna empresa. Por largo tiempo se designó la planta con el nombre de "petún" que le daban los naturales de Brasil (petun latifolium). Las semillas del tabaco fueron llevadas por Fray Román Panes a España en 1518, después a Portugal y a Japón en 1573, por el nuncio papal a Italia y por Walter Raleigh a Inglaterra en 1565. Jean Nicot de Villemain, embajador de Francia ante la corte portuguesa, envió en 1560, a la reina madre de su país esta hierba con presuntas propiedades medicinales que él habría comprobado, y de su apellido Nicot, se deriva el nombre botánico Nicotiana Tabacum y de su alcaloide, la Nicotina.

El uso del tabaco se difundió rápidamente por Europa y su monopolio constituyó una fuente de riqueza para España, Portugal e Inglaterra.

En América, numerosos cronistas se refieren al hábito y costumbres del tabaquismo entre los aborígenes. El doctor Francisco Hernández protomédico de Nueva España entre 1571 y 1577 escribe lo siguiente:

"Al jetl lo llaman los haitianos tabaco porque se mezclan a los sahumerios que igual llaman tabacos. Sus propiedades son bien conocidas: las hojas puestas a secar, envueltas luego en forma de tubo e introducidas en canutos o en canales de papel, encendidas por un lado, aplicadas por el otro a la boca o a la nariz, y aspirando el humo con boca y nariz cerradas para que penetre el vapor hasta el pecho, provocan admirablemente la expectoración, alivian el asma como por milagro, la respiración difícil y las molestias con- siguientes... Se embota el sentido de las penas y trabajos, e invade por completo el ánimo como un reposo de todas las facultades, que podría llamarse casi una embriaguez... El polvo de las hojas, aspirado y tomado por la nariz, hace que no se sientan los azotes ni los suplicios de cualquier género, incrementa el vigor y fortalece el ánimo para sobrellevar los trabajos...”.

El fraile capuchino español, Francisco de Ajofrín que permaneció en la Nueva España de 1763 a 1767 consignó en su diario de viaje:

"El tabaco de hojas es otro abuso de la América. Lo fuman todos, hombres y mujeres; hasta las señoritas más delicadas y melindrosas, y éstas se encuentran en la calle, a pie y en coche, con manto de puntas y tomando su cigarro.... Los religiosos y clérigos también se encuentran en las calles tomando el cigarro, habiéndose acostumbrados desde niños a este vicio, y creo lo aprenden, con otros, de las amas de leche, que aquí llaman chichiguas y generalmente son mulatas o negras. Y como esta viciosa costumbre se ve autorizada por las personas del primer carácter, se comunica fácilmente a los que pasan de Europa, siendo el consumo de tabaco exorbitante, pues apenas dejan el cigarro de la mano en todo el día, excepto el tiempo que está en la iglesia, cuyo lugar sólo está exento de este vicio, pero no en las sacristías...".

El hábito tabáquico se hizo universal iniciado el siglo XX. Originalmente los cigarrillos eran auto-manufacturados y caros. En 1876 los fabricantes de cigarrillos Allen \& Ginter ofrecieron un premio a quien desarrollara una máquina que 
acelerara el proceso de la fabricación de cigarrillos. Cuando James Albert Bonsack desarrolló una máquina que podía hacer 70.000 cigarrillos en 10 horas Allen \& Ginter la rechazaron por el temor que ello superara largamente la demanda. James Buchanan Duke no tuvo esas aprensiones y adquirió dos de esas máquinas y algunos años después llegó a ser presidente de la nueva American Tobacco Company.

La primera guerra mundial ayudó a popularizar el consumo del tabaco. Los soldados en las trincheras fumaban para aliviar la tensión así como muchos civiles. El general John Pershing (Black Jack) le contestaba a un reportero: "Usted me pregunta que necesitamos para ganar esta guerra. Mi respuesta es tabaco y balas".

En las siguientes décadas cientos de miles siguieron "disfrutando el cigarrillo hasta que apareció el primer reporte del Cirujano General de EE.UU. en 1964 (Figura 3).

Este famoso informe despertó por primera vez la alarma pública acerca del peligro del hábito tabáquico y desde esa fecha las curvas de la incidencia de cáncer pulmonar empezaron lentamente a disminuir y a aplanarse, al menos en los varones.

Una encuesta Gallup realizada en 1958 encontró que sólo el $44 \%$ de los estadounidenses creían que el fumar causaba cáncer. En la misma encuesta en 1968 este porcentaje aumentó a 78\%.

En 1965 el Congreso de EE.UU. exigió que todos los paquetes de cigarrillos en el país de-

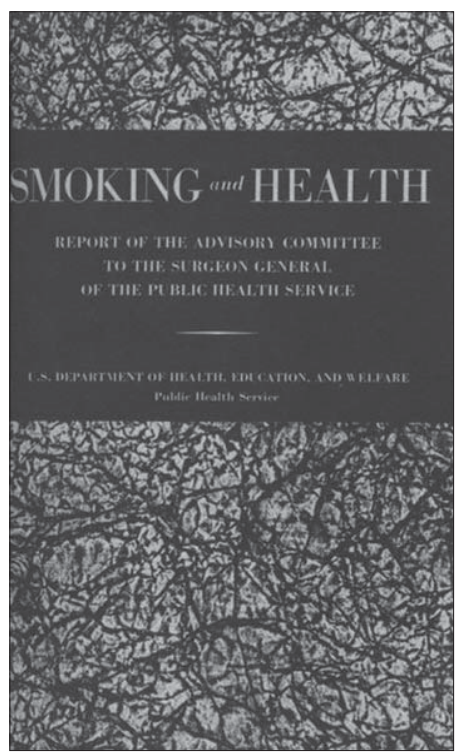

Figura 3. Primera edición del informe del Comité de Consejo para el Cirujano General del Servicio de Salud Pública de EE.UU., 1964. bían llevar advertencias de salud, y en 1969 la propaganda de cigarrillos fue prohibida en radio y televisión.

Actualmente, se reconoce al tabaquismo como el principal responsable del cáncer pulmonar. Sin embargo, es sorprendente cuanto se demoró la incorporación de este conocimiento a las costumbres y a las legislaciones.

En el año 1995 se presentó al Congreso de EE.UU. el informe Brown y Williamson que denunciaba a las grandes compañías tabacaleras el haber conocido los riesgos de adicción y muerte del tabaco y que utilizaron un sofisticado sistema de estrategias legales y públicas para evitar que esos conocimientos las perjudicaran, aunque 30 años antes ellos reconocieron que la nicotina era adictiva y "biológicamente activa" (o sea, carcinogénica). Producto de esa política se produjeron bellos anuncios de propaganda de marcas de cigarrillos con imágenes de médicos (Figura 4).

Esto que nos parece tan escandalosos podemos compararlo en nuestro país con los médicos fumando en los hospitales que conocimos en la segunda mitad de la década de los ' 60 , o bien hoy en día como el cartel que está en el parque del Hospital del Salvador invitando a los funcionarios a fumar o la realidad de los estudiantes de medicina de la Universidad de Chile que, en la encuesta personal que realizo anualmente en las clases de cáncer pulmonar, es de no menos del 10\% de los futuros médicos fuman el día de hoy (Figura 5).

Las encuestas del tabaquismo entre nosotros son verdaderamente preocupantes. Mientras los países desarrollados disminuyen sus cifras de fumadores y muy especialmente en la juventud nosotros mantenemos una lamentable estabilización en cifras muy elevadas sin claras tendencias a disminuirlas (Figuras 6 a 8).

\section{La realidad actual del cáncer pulmonar en el mundo y en Chile}

En 2020 el cáncer pulmonar será la $5^{\text {a causa de }}$ muerte en el mundo.

Hoy el cáncer pulmonar es una enfermedad frecuente que en Chile lleva a la muerte a 2.500 personas anualmente y en el mundo sobre un millón, especialmente en el mundo subdesarrollado (Figura 9).

En los Estados Unidos hubo en 1950, 18.318 muertes por esta enfermedad y en 2010 hubo 172.000 nuevos casos, representando el 13\% de todos los cánceres que ocurren en ese país y el $28 \%$ de todas las muertes por cáncer que ocurren en EE.UU. La mortalidad por cáncer pulmonar en 


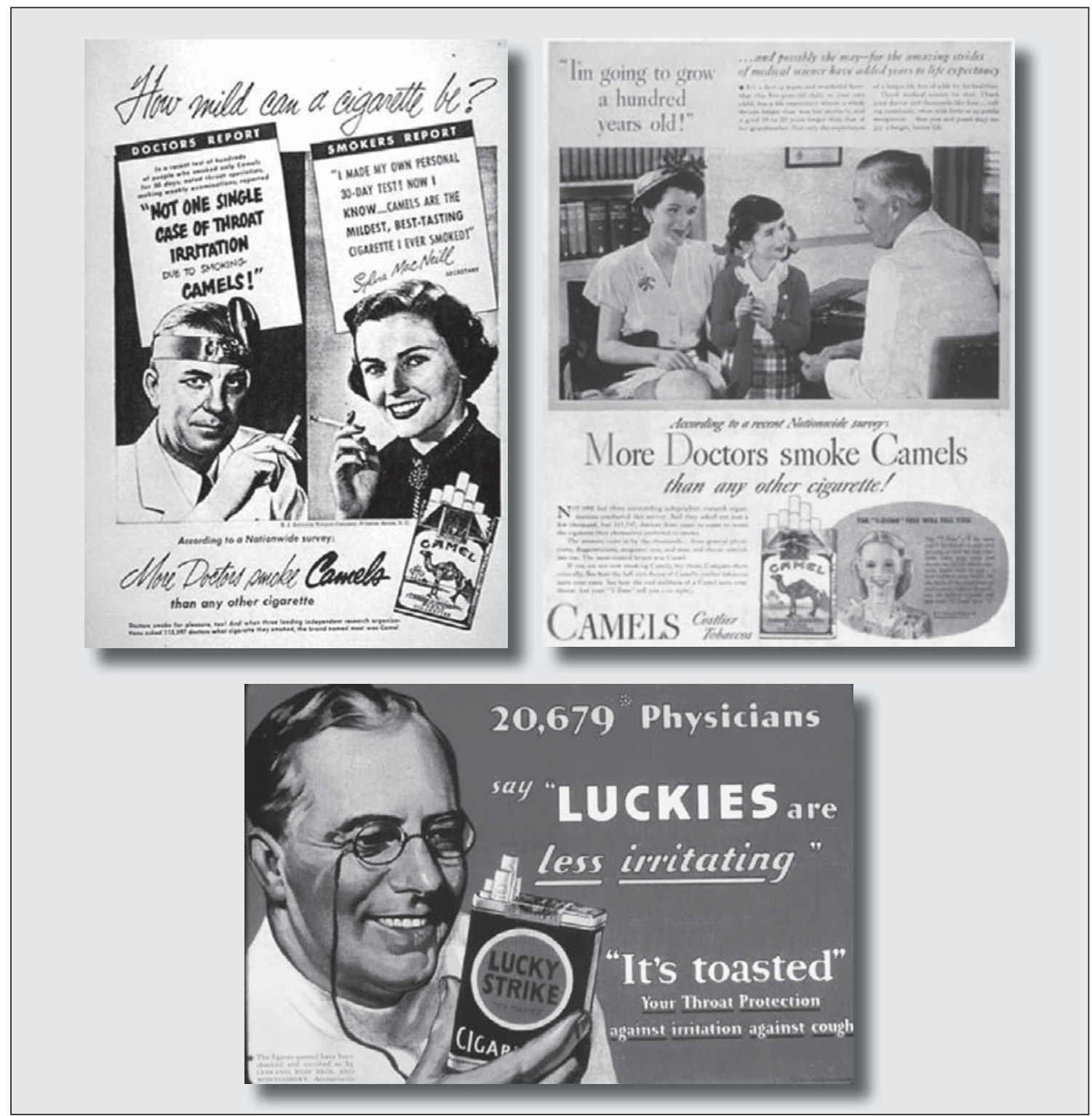

Figura 4. Afiches de propaganda de cigarrillo con referencias a los médicos. Muchos de ellos aparecieron en las principales revistas médicas de la época.

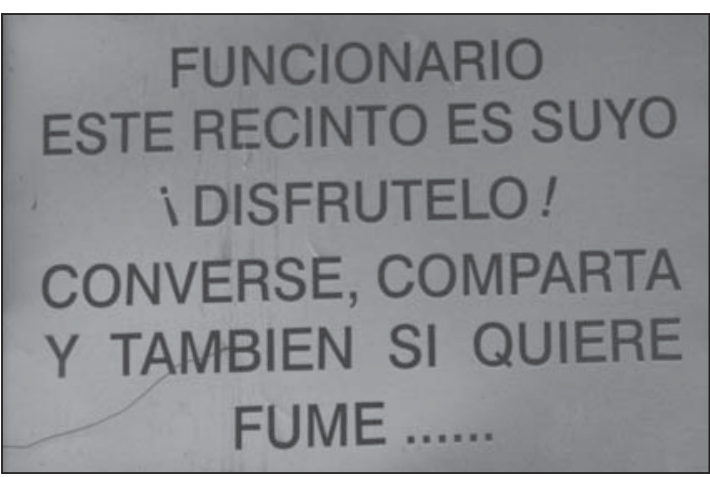

Figura 5. Letrero invitando a fumar en uno de los patios del Hospital del Salvador que puede observarse hoy. dicho país es mayor que la suma de muertes por los cuatro otros cánceres más frecuentes.

Sin embargo, si analizamos la tendencia de las curvas de mortalidad en el mundo desarrollado la frecuencia va disminuyendo, paralelamente a la disminución del hábito tabáquico. Lamentablemente no es así nuestra realidad (Figura 10).

\section{Medios diagnósticos en tiempo del Prof. Alessandri y después}

En los tiempos del Prof Alessandri y del Prof 


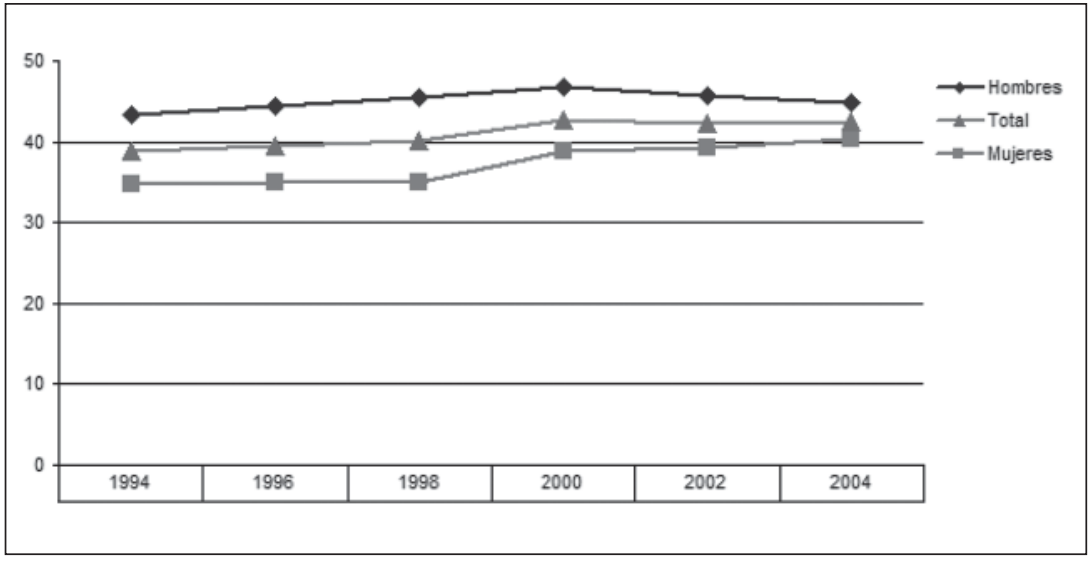

Figura 6. Evolución del consumo de cigarrillos en población general chilena de 12 a 64 años según prevalencia del último mes 1994-2004. En la ordenada se indica el $\%$ de fumadores.

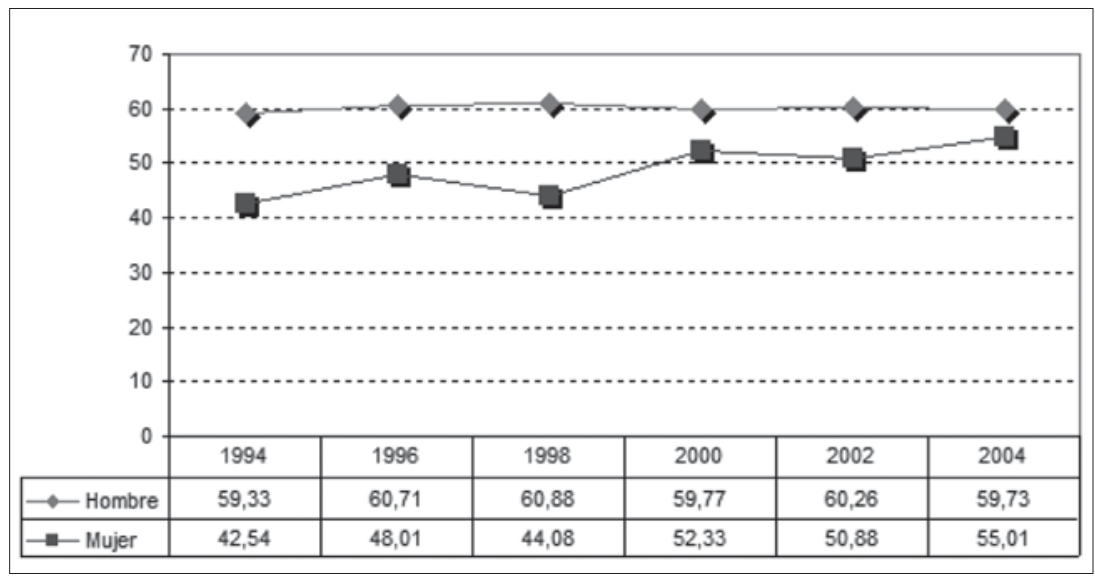

Figura 7. Evolución del consumo de cigarrillos en jóvenes de 19 a 25 niñosaños de edad según prevalencia de último mes por sexo Decenio 1994-2004. Se indica el \% de fumadores.

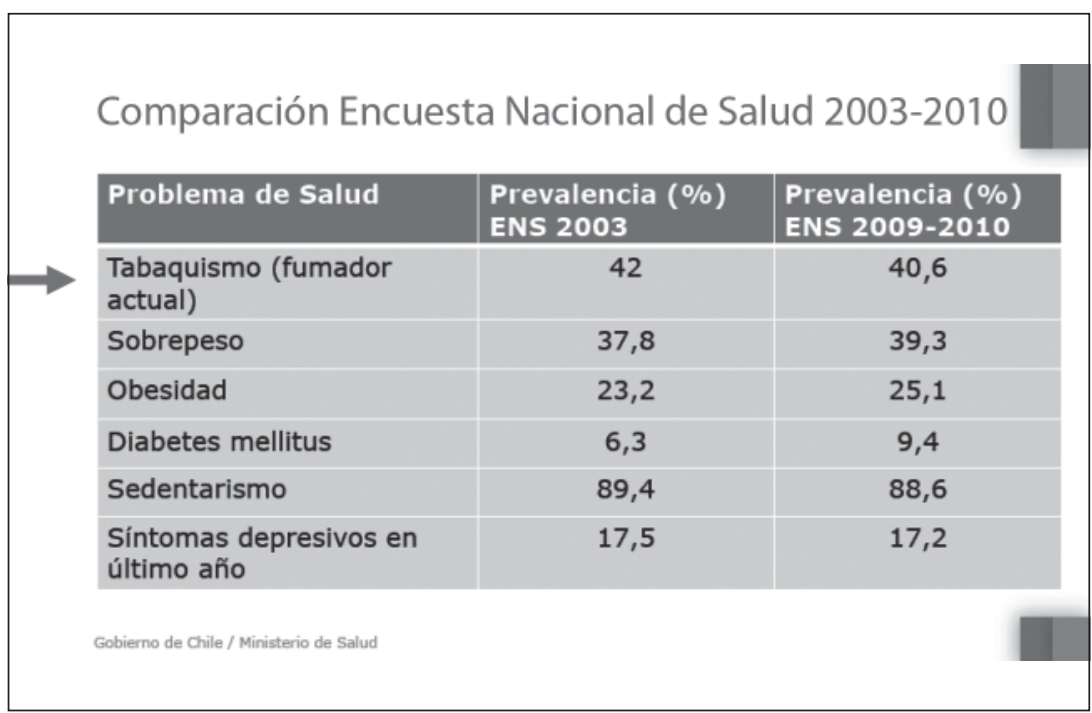

Figura 8. Encuesta Nacional de Salud (ENS). Ministerio de Salud, Chile. 
Jiménez Díaz en España, las armas que se disponía para el diagnóstico de esta enfermedad eran sumamente básicas. La sospecha diagnóstica, al no conocer la causa ya era débil y prácticamente se iniciaba con la radiografía de tórax que como vimos más arriba eran de muy deficiente calidad.

Un cambio fundamental en el análisis radiológico se produjo a mediados de los '70 cuando la tomografía computada fue descubierta independientemente por un ingeniero británico Sir Godfrey Hounsfield (Figura 11a) y el Dr. Alan Cormack en la Universidad de Massachussets, EE.UU.

Fue tal el impacto en el diagnóstico médico que tuvo este aporte que ambos obtuvieron el premio Nobel de Medicina el año 1974. El scanner se comenzó llamando EMI scan pues fue creado en una rama de investigación de EMI, industria musical que se desarrolló en base a ser el sello grabador de los Beatles. El primer EMI scan fue para cerebro y se demo-

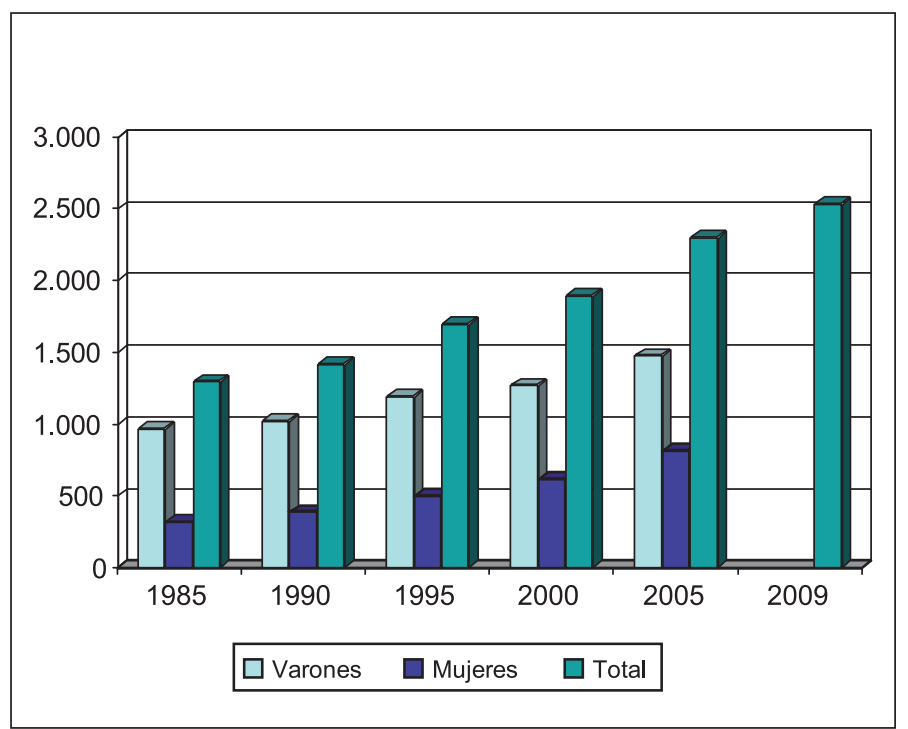

Figura 9. Mortalidad por cáncer pulmonar en Chile desde los años 1985 al 2009.En la ordenada se expresan las muertes por 100.000 habitantes.

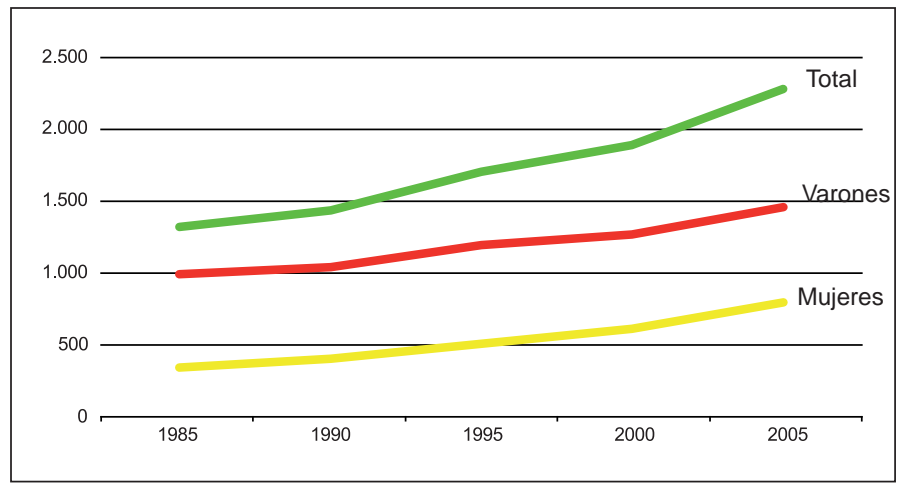

Figura 10. Muertes por cáncer Pulmonar en Chile En la ordenada se expresan las muertes por 100.000 habitantes. raba 12 minutos en el proceso. Los scanner se instalaron en EE.UU. a contar de 1974 y hasta el 2007, sólo en EE.UU. se habían realizado 72 millones de TAC.

En Chile el primer TAC fue instalado en 1978 en el Centro Radiológico Fleming por el gran y recordado radiólogo Dr. Juan Sabbagh quien fue pionero en nuestro medio de tan magnífica innovación (Figura 11b).

La tecnología actual permite lograr un TAC de cuerpo completo en escasos minutos con imágenes de extraordinariamente alta resolución.

Hace apenas 10 años se ha agregado al TAC de tórax una formidable arma diagnóstica que es la tomografía de emisión de positrones o PET que se asocia al scanner constituyendo el PET SCAN. Fue inventado por los Drs. Ron Nutt y David Townsend. La revista Time lo catalogó como la invención del año 2000. Las primeras generaciones incluían sólo PET y actualmente lo combinan con scanner brindando un examen de gran precisión anatómica más información sobre la metabolización de glucosa marcada, propia de las células de rápida reproducción, siendo un extraordinario método de detección de metástasis.

La confirmación de la sospecha que brindaba la radiografía de tórax muchas veces no se lograba, aunque la citología de esputo, descrita por primera vez por Walshe en 1843 y posteriormente investigada sistemáticamente por Dudgeon y cols del St Thomas Hospital de Londres, solía ser de utilidad.

Para la confirmación diagnóstica se usaba la broncoscpía con tubo rígido. Este instrumento tiene una interesante historia. Hipócrates 300 años AC aconsejaba la introducción de un tubo en la laringe de un paciente sofocado y Avicena de Bukhara en el año 1000 DC usó un tubo de plata con el mismo propósito. Por centurias sin embargo, más de la mitad de las inhalaciones casuales de cuerpos extraños llevaban a la muerte o a enfermedades crónicas por infección, abscesos, fístulas o desnutrición. En 
1846 Horace Green presentó a la Academia de Ciencias Médicas de Nueva York su "Tratado de las enfermedades de las vías aéreas" lo cual fue tachado de "... suposición monstruosa, ridículamente absurda y físicamente imposible, una imposibilidad anatómica e injustificada innovación en la práctica médica". Green fue expulsado de la sociedad.

Unos pocos años después, Kollofrath ayudante de Gustav Killian del Policlínico de la Universidad de Friburgo en Alemania escribía en septiembre de 1897 en la Munchener Medicinishe.

"En Marzo 30 de este año he tenido el honor de ayudar a mi admirado maestro el señor Profesor Killian en extraer una pieza de hueso desde el bronquio derecho. El caso es de tal peculiaridad con respecto a su diagnóstico e importancia terapéutica que una descripción más extensa parece justificada".

Killian (Figura 12a) realizó varios ensayos en cadáveres e hizo su primera endoscopía en un voluntario, llegando con el instrumento a nivel lobar y ese mismo año hizo la primera extracción de cuerpo extraño referida más arriba. Posteriormente publicó 34 trabajos sobre este nuevo método y Friburgo llegó a ser un centro internacional de realización del procedimiento desarrollándose hasta 20 cursos de entrenamiento por año.

En EE.UU., A. Coolidge el 11 de mayo de 1898 realizó la primera traqueobroncoscopía en el Massachussets General Hospital, pero fue Chevalier Jackson en Philadelphia (Figura 12b), quien modificó el broncoscopio agregándole iluminación propia y desarrolló la técnica, apareciendo el primer broncoscopio norteamericano en 1904.
En 1907 Jackson publicó el primer texto sistemático de broncoscopía dedicándoselo a Killian como el padre de la broncoscopía. Es destacable que este autor siempre rechazó patentar sus inventos con la intención que se diseminaran lo más posible en beneficio de los pacientes.

La broncoscopía rígida fue un instrumento diagnóstico fundamental hasta mediados de los 60 y hasta esa fecha se usó el broncoscopio de Chevalier Jackson prácticamente sin modificaciones. Hasta el día de hoy se usa esta técnica, ahora en manos de cirujanos y en pabellón y anestesia general, muy distinto a lo que conocimos antes de 1966.

Nuestro Pablo Neruda también conoció la broncoscopía rígida como nos cuenta en su bello poema "Laringe" en su libro Estravagario:

Ahora ya de veras dijo

La Muerte y a mí me parece que me miraba, me miraba. Esto pasaba en hospitales, en corredores agobiados y el médico me averiguaba con pupilas de periscopio. Entró su cabeza en mi boca, me rasguñaba la laringe:

allí tal vez había caído

una semilla de la muerte.

Y más adelante

Con estas vociferaciones

mentales me sostenía mientras el doctor intranquilo se paseaba por mis pulmones: iba de bronquio en bronquio como
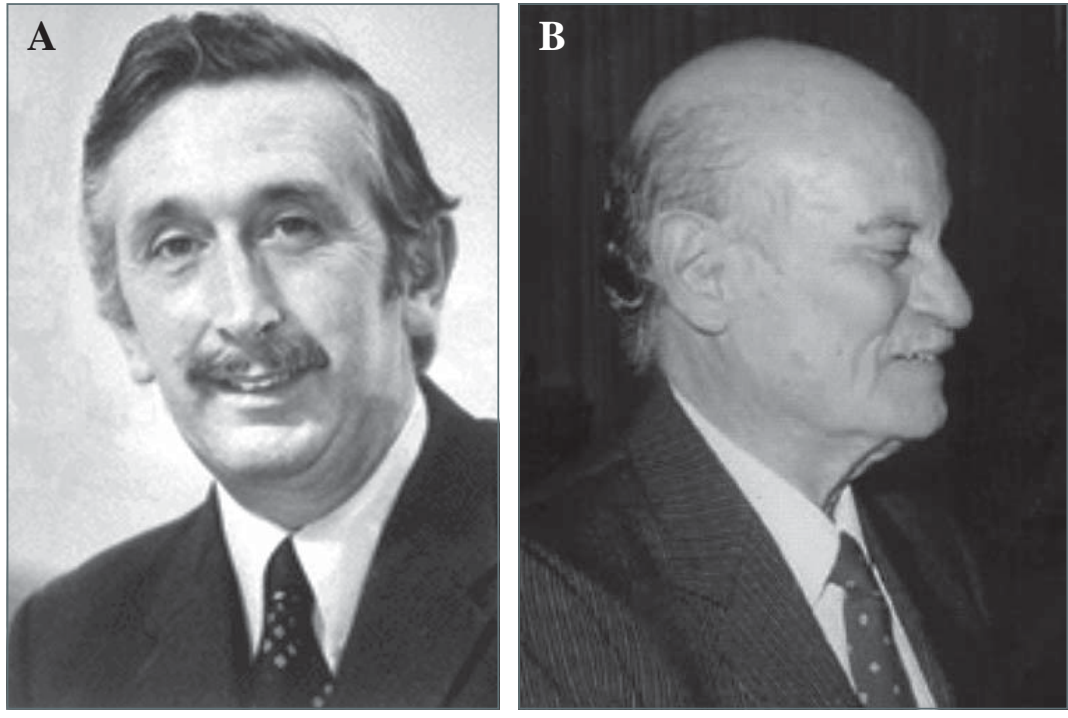

Figura 11. A: Sir Godffrey Hounsfield. Nobel de Medicina 1979. B: Dr. Juan Sabbagh D. 
pajarillo de rama en rama:

yo no sentía mi garganta

mi boca se abría como

el hocico de una armadura

y entraba y salía el doctor

por mi laringe en bicicleta

hasta que adusto, incorregible,

me miró con su telescopio

y me separó de la muerte.

1966 fue un año muy importante en la historia de la broncoscopía cuando Ikeda introdujo el primer broncofibroscopio de fibra óptica (Figura 12c). Para quienes vivimos la época del broncoscopio rígido, "la pata del catre "como gráficamente la llamaban los pacientes, el broncofibroscopio de fibra fue un invento casi milagroso, tanto por su alcance diagnóstico como por su tolerabilidad por parte de los pacientes a diferencia del heroico tubo rígido.

Los últimos años han traído numerosos y sorprendentes avances en Broncofibroscopía. La exploración del mediastino a través de este instrumento se inició con las punciones transtraqueales y transbronquiales por medio de la llamada aguja de Wang.

Muy poco después surgió la posibilidad de incorporar el ultrasonido a través de la broncoscopía apareciendo la endosonografía bronquial: EBUS que permite a través de ultrasonido reconocer ganglios mediastínicos y biopsiarlos.

La técnica ha sido tan exitosa y se ha difundido tan rápidamente que hoy día hay muchos centros que han comunicado su experiencia que prácticamente reemplaza la mediastinoscopía. Esta técnica puede también localizar y biopsiar nódulos más periféricos y por otra técnica, la llamada navegación electromagnética se puede llegar prácticamente a cualquier nódulo dentro del pulmón.

Como vemos, la diferencia de recursos diagnósticos entre la actualidad y la década previa a los años '70 es enorme. ¿Cómo se ha traducido ese gran avance de los medios diagnósticos en los resultados terapéuticos en cáncer pulmonar?

\section{Terapéutica en cáncer pulmonar}

En la época del Profesor Alessandri el único recurso terapéutico en cáncer pulmonar era la cirugía. Veamos pues como fue el desarrollo de la cirugía en cáncer pulmonar:

\section{Cirugía del cáncer pulmonar}

A comienzos del siglo XX sólo muy osados cirujanos en Alemania y en EE.UU. se atrevían a realizar cirugía torácica, con alta mortalidad $(\sim 50 \%)$.

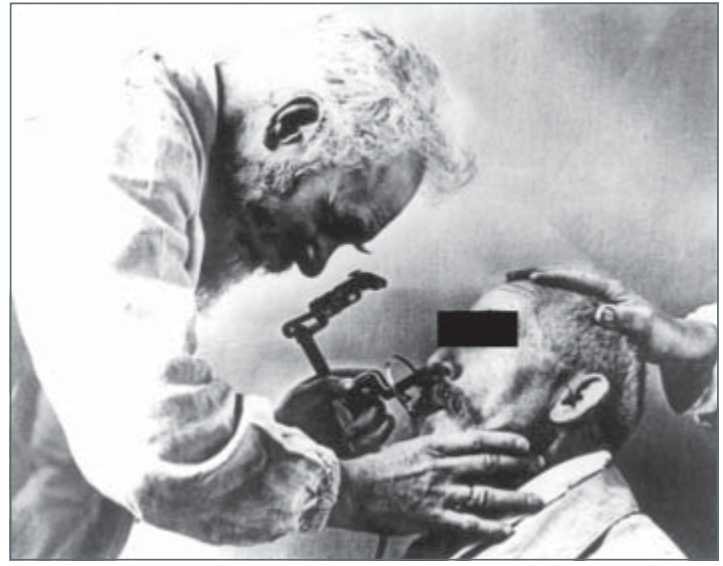

Figura 12a. Gustav Killian examinando con su broncoscopio.

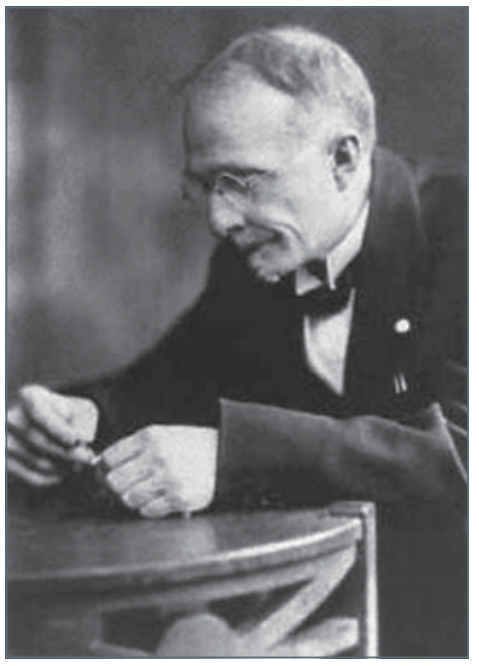

Figura 12b. Chevalier Jackson (1865-1958), padre de la endoscopía. Filadelfia, EE.UU.

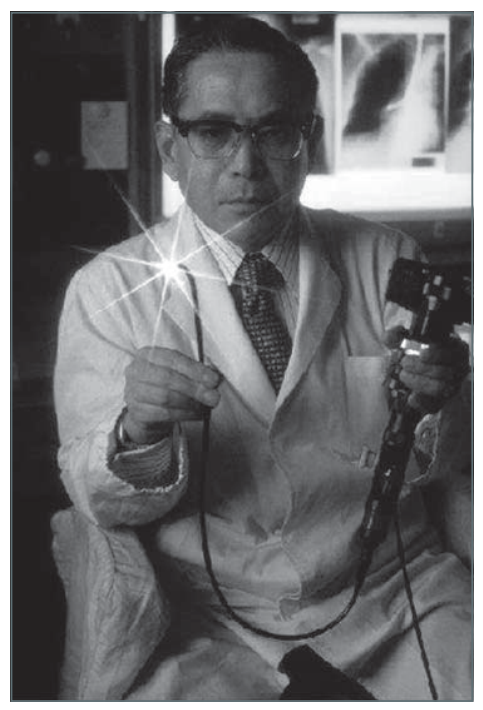

Figura 12c. Dr. Shigeto Ikeda con un Broncofibroscopio en sus manos. Nacional Cancer Center, Japón. 
En 1923 Evarts Graham introdujo un método en el cual el lóbulo se destruía por etapas a través de cauterio y en 1928 Harold Brunn de California introdujo la lobectomía de un tiempo.

La cirugía del cáncer pulmonar fue tardía en relación al resto de la cirugía torácica. La historia del Dr. James Gilmore es muy ilustrativa al respecto. Gilmore era un obstetra-ginecólogo de Pittsburg, de 48 años de edad a quien en abril de 1933 se le diagnosticó un cáncer pulmonar, después de una historia de 7 meses de tos y fiebre. La Rx de tórax demostró una sombra en forma de mariposa con base en zona axilar izquierda y se le recomendó y realizó un neumotórax artificial que le produjo alivio temporal de sus síntomas. Un broncograma con lipiodol demostró una obstrucción del bronquio lobar superior izquierdo. Se le realizaron dos broncoscopías rígidas, la segunda de ellas reveló un tumor del tamaño de una arveja a la entrada del bronquio lobar superior izquierdo. La biopsia demostró un cáncer epidermoide y se le recomendó una lobectomía (Figura 13).

El Dr. Gilmore se fue a su casa, se hizo un trabajo dental y se compró una tumba en el cementerio local. Sin embargo, como graduado de la Escuela de Medicina de la Universidad de Washington conocía la figura de Evarts Graham, un gigante entre los cirujanos estadounidensess y sabía que su cáncer podría requerir una neumonectomía y que todos los intentos hasta ese momento de realizar dicha intervención habían fracasado por hemorragia, sepsis o fracaso de las suturas.

Durante la operación Graham encontró que el carcinoma invadía de tal modo que era imposible salvar el bronquio y que había varios nódulos en la porción superior del lóbulo superior izquierdo, sospechosos de compromiso tumoral. Además la cisura interlobar no era completa por lo que decidió la neumonectomía.

Describe Graham: "Había un aspecto de la

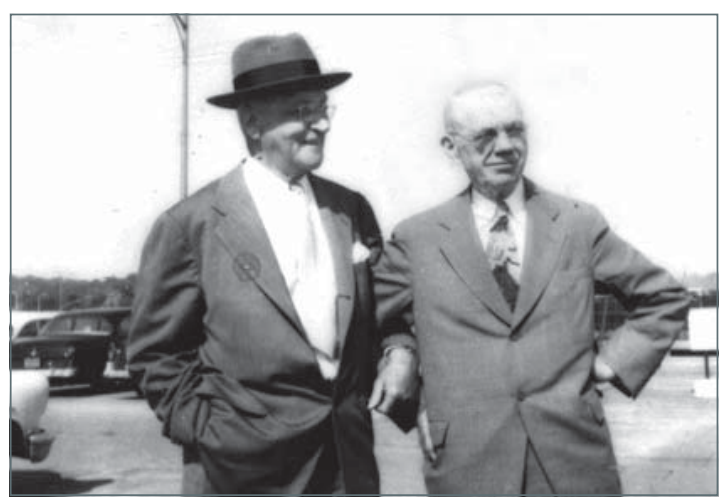

Figura 13. Los Drs. Graham y Gilmore. operación que me preocupaba. Y esto era si un paciente de edad media podría tolerar la brusca oclusión de la arteria pulmonar de un pulmón. Por lo tanto, le comuniqué al anestesista que planeaba ocluir la arteria pulmonar bruscamente y quería que me comunicara cualquier cambio que ocurriera en el pulso, la respiración o el color del paciente. Entonces pasé un catéter de goma alrededor de la arteria que pudiera soltar si había problemas. Después de 90 segundos con el paciente estable sentí que era seguro continuar. Al acabar la cirugía y "horrorizado por el tamaño de la cavidad torácica que quedaba luego de extraer el pulmón, procedí a sacar varias costillas para permitir el colapso torácico sobre el mediastino. Toda la cirugía duró una hora y 45 minutos".

El paciente estuvo 75 días en el hospital, perdió $10 \mathrm{~kg}$ de peso y un mes después del alta le escribe a Graham que había subido de peso, ganaba en fuerzas y el ánimo era bueno.

El Dr. Gillmore continuó ejerciendo por 24 años y murió en 1963 sin ninguna evidencia de cáncer a pesar que continuó fumando por el resto de su vida.

De acuerdo a Mountain, el gran cirujano de tórax de Houston, Texas, la neumonectomía de Graham fue la levadura que estimuló y vigorizó todo el campo de la cirugía pulmonar y el catalizador esencial en el desarrollo del tratamiento moderno del cáncer pulmonar. De hecho ese mismo año 1933 en Montreal y en Baltimore realizaron neumonectomías en un tiempo exitosas.

Es posible que la primera neumonectomía en un tiempo del mundo la realizara el cirujano alemán Herman Kummel como el propio Graham lo sugiere en su artículo del JAMA, pero el paciente no sobrevivió. Posteriormente a su éxito con la neumonectomía del Dr. Gilmore, Graham realizó 70 cirugías de este tipo en cáncer pulmonar: con 19 muertes consecutivas y sólo 3 muertes en los casos restantes con una mortalidad total de $30 \%$ cuando tal cirugía tenía en esos años una mortalidad cercana al $100 \%$. Es curiosa la ironía de la vida. El Dr. Graham murió de un cáncer pulmonar y se conserva la carta en que le comunica la infausta noticia al Dr. Gillmore con el cual se hicieron grandes amigos. Algunos párrafos de esa carta de febrero de 1957, son los siguientes:

...supongo que habrás oído ....acerca de la ironía que el destino me ha jugado ...se encontró en la Rx de tórax que tengo un carcinoma broncogénico con compromiso bilateral.

Una cirugía exploradora reveló que tengo compromiso de la grasa escalénica. Ahora estoy en mostaza nitrogenada y muy inconfortable... 
Tú sabes que yo había dejado de fumar hace 5 años. Probablemente algunos dirán que mi caso niega la idea de la conexión cigarrillo cáncer, de lo cual no participo pues al fin y al cabo yo fumé 50 años antes de detenerme...

...Trataré de llevar esto tan largo y tan bien como pueda....

Curiosamente, se mantuvo por un largo período la neumonectomía como la cirugía de elección en el cáncer pulmonar e incluso hay una publicación de dos importantes cirujanos torácicos los Drs. Ochsner y DeBakey en 1939 en que la defienden como una lógica cirugía en vez de la lobectomía en cáncer pulmonar. Sólo en 1962 Shimkin con datos de la clínica Oschner y Overholt afirman y publican por primera vez mejoría de la sobrevida en cánceres localizados versus extensos independiente de la cirugía realizada (Figura 14).

Y esto que nos parece tan lógico hoy en día fue una novedad en ese tiempo.

La neumonectomía hoy en día ha pasado a ser una cirugía de excepción y hoy se discute si la lobectomia presenta ventajas sobre la segmentectomía en cáncer pulmonar, cuando ésta puede realizarse después de una completa etapificación del paciente.

Un notable avance en la cirugía torácica en general y del cáncer pulmonar en particular ha sido la incorporación de la videotoracotomía, procedimiento que en la actualidad y en muy breve tiempo tiende a tornarse en rutinario en el abordaje del cáncer pulmonar.

\section{Clasificación TNM}

El sistema de clasificación de los cánceres fue originalmente propuesto por Pierre Denoix en Francia entre los años 1943 y 1952. Este sistema brinda una descripción anatómica consistente y reproducible de la extensión del cáncer en los pacientes.

Clifton Mountain, (Figura 15a) cirujano torácico de Houston que nos visitó varias veces, fue el primero que adaptó tal clasificación al cáncer pulmonar. En 1973 y en 1986 presentó el sistema de clasificación basado en 13 años de experiencia y rápidamente fue incorporado universalmente como pieza fundamental en el diagnóstico y la elección de terapia en cáncer del pulmón. Luego del diagnóstico se determinará el tamaño y localización del tumor $(\mathrm{T})$, la presencia o ausencia de compromiso ganglionar $(\mathrm{N})$ y si el tumor tiene o no metástasis a distancia (M). (Figura 15b).

La uniformidad en los criterios de etapifica- ción del tumor asegurará a cada paciente una mejor elección de terapia, evaluará su operabilidad y se podrá estimar el pronóstico con mucha seguridad. Por otro lado, permite comparar el resultado de protocolos de tratamiento en diferentes centros. Desde la publicación de Mountain hasta el presente se ha avanzado considerablemente en este sistema con una proposición de 2007 que alcanza una sorprendente precisión en los objetivos que ella propone (Figura 15c).

\section{Otras armas terapéuticas en el cáncer pulmonar}

La era de la quimioterapia en el cáncer se inició en los '40 con el uso inicial de mostazas nitrogenadas y antagonistas del ácido fólico. A comienzo de los ' 40 un bombardeo aéreo en Bari, Italia expuso a miles de personas a gas mostaza, contenido en las bombas. Las autopsias de las víctimas sugerían una profunda depresión linfoide y mieloide. Usando esa información Louis Goodman y Alfred Gilman, dos importantes farmacólogos contratados por el Departamento de Defensa de EE.UU. para investigar las potenciales capacidades terapéuticas de los agentes químicos de guerra razonaron la posible utilidad de tales agentes en el tratamiento de los linfomas, lo cual demostraron posteriormente en el animal de experimentación y en el ser humano.

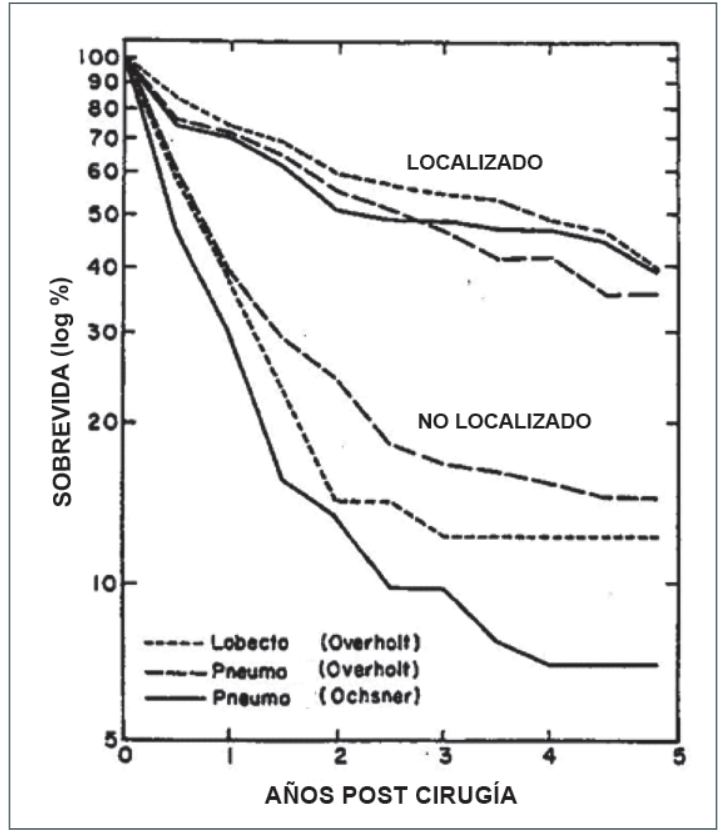

Figura 14. Neumonectomía (Pneumo) versus lobectomía (Lobecto) en cáncer pulmonar. Curvas de sobrevida por etapas y procedimientos quirúrgicos (Modificada de $\mathrm{J}$ Thorac Cardiovascular Surg 19662; 44: 503.). 


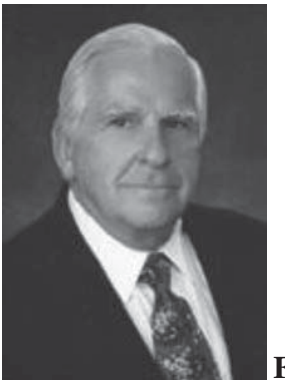

Figura 15a. Dr. Clifton Mountain.

\begin{tabular}{|c|c|c|c|}
\hline \multirow[t]{2}{*}{ Estadio } & \multirow[t]{2}{*}{ Descripción TNM } & \multicolumn{2}{|c|}{ Sobrevida a los 5 años, $\%$} \\
\hline & & $\begin{array}{l}\text { Estadio } \\
\text { Clínico }\end{array}$ & $\begin{array}{c}\text { Estadio Quirúrgico- } \\
\text { Patológico }\end{array}$ \\
\hline IA & T1 NOMO & 61 & 67 \\
\hline IB & T2 NO MO & 38 & 57 \\
\hline$\| \mathrm{A}$ & T1 N1 M0 & 34 & 55 \\
\hline IIB & T2 N1 M0 & 24 & 39 \\
\hline IIB & T3 NOMO & 22 & 38 \\
\hline \multirow[t]{2}{*}{ IIIA } & T3N1 M0 & 9 & 25 \\
\hline & $\mathrm{T} 1-2-3 \mathrm{~N} 2 \mathrm{MO}$ & 13 & 23 \\
\hline \multirow[t]{2}{*}{ IIIB } & T4 N0-1-2 MO & 7 & $<5$ \\
\hline & $\mathrm{T} 1-2-3-4$ N3 MO & 3 & $<3$ \\
\hline IV & $\begin{array}{l}\text { Cualquier } \mathrm{T} \text { cualquier } \mathrm{N} \\
\text { M1 }\end{array}$ & 1 & $<1$ \\
\hline
\end{tabular}

Figura 15b. Clasificación TNM del cáncer pulmonar Clifton Mountain 1997.

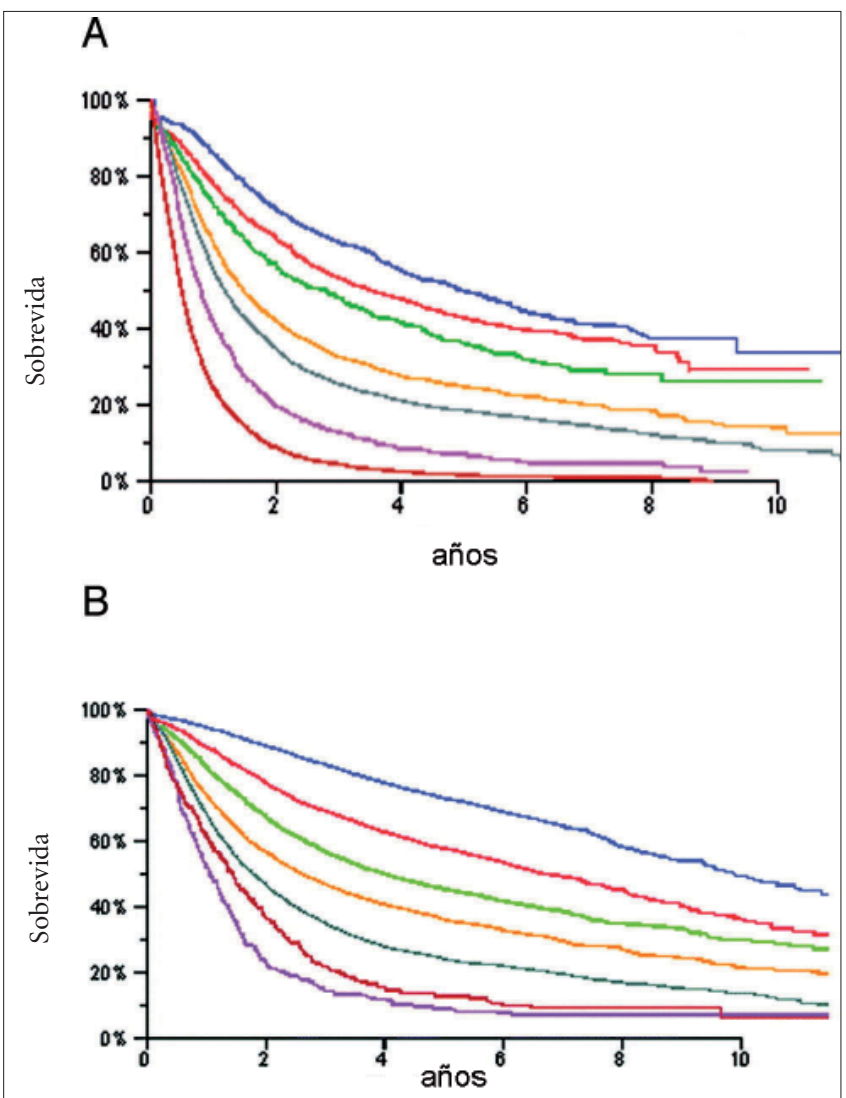

Figura 15 c. Clasificación TNM del cáncer pulmonar, $7^{\mathrm{a}}$ edición 2007 con las curvas de sobrevida para cada etapa. El gráfico A representa las etapas TNM evaluadas clínicamente. El gráfico B representa las etapas TNM evaluadas por anatomía patológica. Las 7 curvas de sobrevida de ambos gráficos corresponden de arriba hacia abajo a las siguientes etapas: IA; IB; IIA; IIB; IIIA; IIIB y IV.
Sin embargo, los intentos de uso de estos agentes en cáncer pulmonar no fueron exitosos hasta los años ' 70 cuando se empezaron a utilizar combinaciones de drogas en base a platino. Esto fue liderado por los investigadores del Eastern Cooperative Oncology Group (ECOG) quienes emprendieron una serie de protocolos de investigación a gran escala para identificar los regímenes óptimos de terapia para el cáncer de células pequeñas en etapas avanzadas. Estos estudios que se desarrollaron en los '70 y ' 80 concluyeron demostrando que las respuestas objetivas se obtuvieron en alrededor del $25 \%$ de los casos con una sobrevida promedio de 1 año. Es interesante la historia del platino como agente antineoplásico. Este fue descubierto en la Universidad de Michigan por Barnett Rosenberg en forma casual. Rosenberg exploraba los posibles efectos de un campo eléctrico en el crecimiento bacteriano y observó que las bacterias inesperadamente dejaban de crecer cuando se exponían a un campo eléctrico. Después de meses pudo demostrar que la falta de crecimiento era causado por la electrolisis del electrodo de platino más que por el campo eléctrico propiamente tal. Esto llevó a investigaciones que concluyeron que el platino actuaba en la división celular.

De acuerdo a lo demostrado en animales de experimentación las drogas fueron más efectivas cuando se usaron en tumores de menor volumen.

Esta forma o "terapia adyuvante" se ha explorado en cáncer pulmonar y se ha demostrado que un volumen considerable de cánceres pulmonares operados se benefician con terapia adyuvante.

Sin embargo, lo más espectacular y que está ocurriendo en estos momentos han sido las aproximaciones genéticas y moleculares a la biología celular descubriendo señales enteramente nuevas que regulan una malla de actividades celulares como la proliferación y la sobrevida. Se ha encontrado que estas redes están profundamente alteradas en cáncer y estas alteraciones tienen una base genética causadas por mutaciones somáticas, lo cual ha abierto un gran camino de manejo terapéutico. Un ejemplo que ya va siendo clásico es el desarrollo 
de moléculas como la tirosinkinasa y el Imatinib mesilato que inhiben a las moléculas de señales.

También los anticuerpos monoclonales se han usado en esta línea. Estos son proteínas inmunes que pueden unirse casi a cualquier blanco. Derivados de la rata y "humanizados" a través de una transformación genética, han permitido crear una serie numerosa de ellos.

La radioterapia se usa junto a la quimioterapia en aquellos casos localmente avanzados y que están fuera de posibilidades quirúrgicas. En técnicas de aplicación ya sea radioterapia llamada radical o hiperfraccionada. En general la radioterapia juega un papel complementario o bien un gran papel en la paliación

\section{El cáncer pulmonar y el paciente}

El cáncer pulmonar casi siempre está ligado al hábito de fumar y ha recorrido el mundo en nuestros días como las plagas en el pasado o como la guerra, con su reguero de muerte.

¿Cómo vive el paciente de cáncer pulmonar su terrible enfermedad?

¿Cómo vivieron su enfermedad esa larga lista de víctimas que murieron antes de lo que les habría correspondido por ese infausto enemigo del tabaquismo?

¿Cómo lo vivieron grandes actores como Clark Gable, Burt Lancaster...?

¿Cómo lo vivieron médicos neumólogos, como Pedro Valenzuela, Leonel Madariaga, que conocían y habían luchado con el terrible enemigo?

¿Cómo lo vivieron nuestros grandes amigos, médicos neumólogos, amigos de tantos de los presentes y que conocieron y usaron este mismo auditorio, los inolvidables Patricio González y Enrique Fernández? (Figura 16).

No lo sabemos, pero puede iluminarnos el sentimiento de un poeta. Un poeta de selección como Gonzalo Millán que fue paciente del hospital del Tórax, atendido por nosotros y que desde que supo su diagnóstico empezó a escribir un libro con sus vivencias y que se publicó póstumamente.

Veamos algunos párrafos de este estremecedor testimonio:

La mala noticia infiltra los exámenes urgentes y los hace tremendos, lapidarios. El dolor te procesa después de arrollarte. La mortalidad se hace una pena, la vida que te queda un duelo

El profundo desconsuelo,

La demoledora pena por el fin

de la película, infeliz y linda
Mi pérdida de vida, mi golpe mortal, mi abrupto conocimiento del fin, desprevenido, sin advertencia, distraído, incauto

"El cáncer es el destructor de la ignorancia de mi cuerpo,

Se apropia de las riendas de mi respiración,

El cáncer es un faraón que construye con retraso y previsión su tumba subterránea. En tu edad aportillado por aquí y por allá, edifica sus ciudades funerarias.

"Aumentará el desgarro, dolerán las comisuras de la abierta boca, el animal que muere no elige su grito".

Sentirás los pulmones como un fuelle roto.

Te sentirás preso, el rehén aprisionado,

por la enfermedad que hospedas".

"El cáncer te hace pasar a la vejez y cierra la puerta".

"Señor, me siento despedazado, hecho picadillo. Veo como un par de demonios me cocinan y devoran estando vivo todavía.

"No consigo conmover al almendro florido con mis toses.

El cuerpo enfermo deja de ser tuyo con exclusividad, ahora es una propiedad compartida, una propiedad común con amables accionistas".

"Los pulmones enfermos me discordian esa parte de mi cuerpo, me da rabia y resentimiento agresivo (tal vez por eso sigo fumando como una desquiciada venganza). Me siento perplejo y traicionado, víctima de un castigo injusto. Indignado con la muerte”.

"Estando enfermo, todos los días son festivos de una perversa manera, un ocio disponible para el dolor, el sufrimiento. Sobra el ocio disponible para el sufrimiento. Las vacaciones siniestras de pesadilla. Te dan unas vacaciones de pesadilla.

Ir al Hospital del Tórax me demuele y volver sobre los detalle del cáncer me abruma y deprime”.

"En el no saber planteado al final de la vida aparece una deslumbrante y oscura laguna. Una atroz falta de explicaciones, una ausencia de respuesta. Nada, poco sabemos de la vida, y de la muerte menos".

"La muerte resulta ser un caballero circunspecto y grave, severo y austero, carente de sentido del humor.

Un cobrador sin uniforme, un contador usurero.

La noticia de ultimátum irreversible me ha llenado de inquietud y miedo. Parece que una expectativa de ilusión terminó con el remedio alternativo. Empieza otra etapa más real, más 

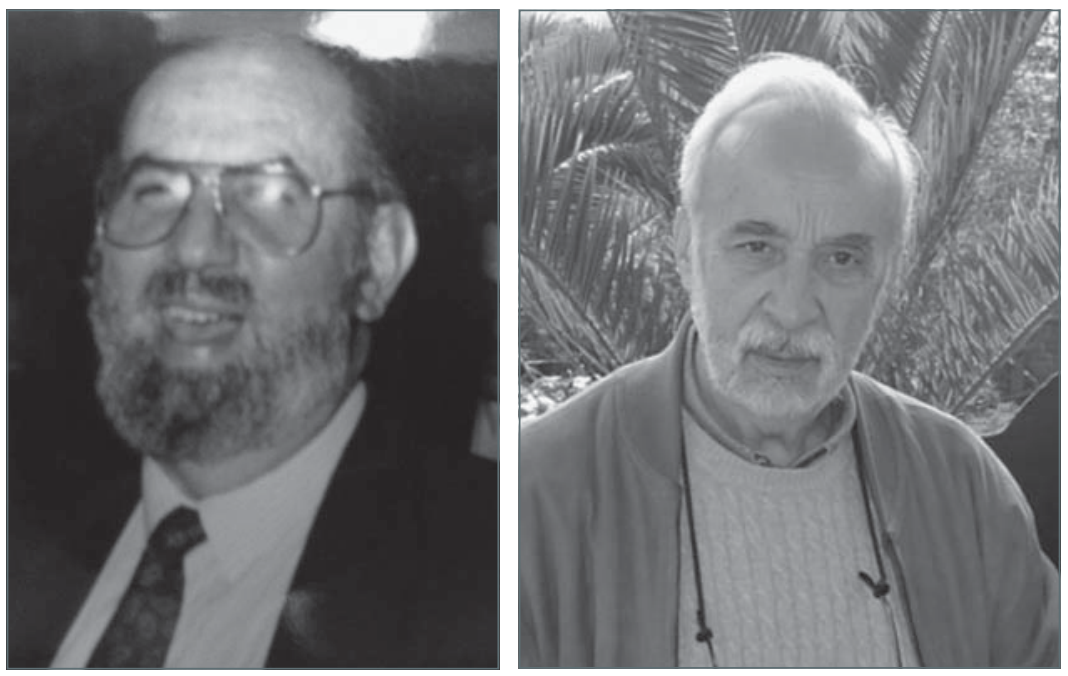

Figura 16. Los Drs. Patricio González y Enrique Fernández, dos distinguidos neumólogos chilenos fallecidos de cáncer pulmonar.

desprovista de ilusión. Poeta y sangre, poeta y tos. Poeta moribundo".

"Cuando llegaron a casa los tubos de oxígeno fue señal para todos de que entrábamos en otra etapa, la del gimnasta agónico. Disuelto, licuado, aniquilado. La muerte, un aviso de corte en trámite".

"¿Qué he hecho yo para merecer la atroz quimioterapia, la endoscopía, la cintigrafía, los rayos, el scanner? fumar.

No me digan que todo eso me pasa sólo por

Fumando humo de espinas

Fumo, toso, sangro

Siempre digo es el último cigarro, mientras el humo se lo come vivo".

\section{Una luz de esperanza}

El cáncer pulmonar es una terrible enfermedad que nos ha asolado con un reguero de muerte. Sin embargo, estamos empezando a ver una luz de esperanza. Veíamos hace unos momentos que el mundo desarrollado está venciendo la lucha contra el hábito tabáquico y las curvas del consumo empezaron a bajar por los años ' 70 y veinte años después la han seguido la caída de las curvas de mortalidad por cáncer pulmonar. Ninguna de estas dos realidades las vemos aún entre nosotros.

Hace sólo algunos meses en el New England Journal of Medicine se dio cuenta de la reducción de un $20 \%$ de muertes específicas por cáncer en el grupo que se realizó pesquisa de cáncer pulmonar a través de la tomografía computada de baja dosis, en un gran estudio randomizado de 53.454 participantes, todos fumadores pesados entre 55 a 74 años seguidos por 6 años y divididos en aquellos en que se realizó la TAC de baja dosis y en los que sólo se efectuó Rx de tórax. Esta es una gran noticia. El refinamiento y utilización creciente de la TAC de tórax está empezando a demostrarse útil en pesquisa con identificación en etapas precoces de cánceres pulmonares previamente invisibles.

Por otro lado, las aberraciones moleculares con significado pronóstico se están identificando y ya son parte de un informe histopatológico óptimo. Ya se están utilizando agentes terapéuticos que pueden beneficiar selectivamente a pacientes con un fenotipo histológico y características moleculares particulares.

Se ha planteado, y ya es posible, diagnosticar y etapificar el cáncer pulmonar de una manera muy precisa. Más que prescribir tratamiento para un paciente con un cáncer pulmonar no células pequeñas etapa IV los clínicos deberían moverse hacia describir el mismo paciente como T2N2 M1a, etapa IV, adenocarcinoma secretor mucinoso $\operatorname{EGFR}(-)$, K RAS (-).

Este detalle diagnóstico que revela el enorme avance en el conocimiento del cáncer pulmonar muy posiblemente nos llevará en un futuro a vencer a este monstruo que creamos.

\section{Bibliografía}

1.- NEGHME A. Hernán Alessandri Rodríguez. Médico, Maestro, Académico y Universitario, su vida y su obra. Editorial Universitaria. Santiago, 1982.

2.- GOIC A. Semblanza del Profesor Dr. Hernán Alessandri R. Rev Med Chile 2005; 133: 1500-3.

3. GOIC A. El Dr. Hernán Alessandri que yo conocí. Rev 
Med Chile 1982; 110: 593-5.

4.- CHAMORRO G. El Dr. Hernán Alessandri y el desarrollo de la Medicina Interna en el Hospital del Salvador. Rev Med Chile 1979; 107: 438-40.

5.- ETCHEVERRY R. Homenaje al Profesor Doctor Hernán Alessandri Rodríguez Academia de Medicina. Rev Med Chile 1982; 110: 401-9.

6.- Lung Cancer. From Wikipedia, the free enciclopedia, $2011 \mathrm{http} / /$ wikipedia.org/wiki/lung cancer (consultada 5.03.2012).

7.- WITSCHI H. A short history of Lung Cancer, Society of Toxicology 2001; 64: 4-6.

8.- HORN H, JOHNSON D J, EVARTS A. Graham and the first pneumonectomy for lung cancer J Clin Oncol 2008; 26: 3268-75.

9.- GRAHAM E. Pneumonectomy with the cautery: a safer substitute for the ordinary lobectomy in cases of chronic suppuration of the lung. JAMA 1923; 81: 1010-12.

10.- Outpatient Lung Cancer Surgery. Lung cáncer Historical Prospective. http://www.lungcancersurgery.org/ lung_cancer_history.htm (Consultada: 5.03.2012).

11.- MOUNTAIN C F. Revisions in the international system for staging lung cancer. Chest 1997; 111: 1710-17.

12.- DE MICHELI A, IZAGUIRRE-ÁVILA R. Tabaco y tabaquismo en la historia de México y de Europa. Instituto Nacional de Cardiología Ignacio Chávez Revista de Investigación Clínica 2005; 57: 608-13.

13.- WYNDER E, GRAM E. Tobacco smoking as a posible etiologic factor in bronchogenic carcinoma: A study of six hundred and eighty-four proved cases. JAMA 1950; 143: 329-36.
14.- DOLL R, HILL B. Smoking and Carcinoma of The Lung Brit Med J 1950; 2 (4682): 739-48.

15.- DOLL R, HILL B. The mortality of doctors in relation to their smoking habits. Brit Med J 1954; 26; 1 (4877): 1451-5.

16.- MEDINA E, PASCUAL J P, CUMSILLE F, ALEGRÍA A, GUTIÉRREZ L, CORVALÁN L, et al. Encuesta de tabaquismo en la población general de Santiago Rev Med Chile 1986; 114: 257-62.

17.- VARGAS N. El hábito de fumar: Epidemia creada por el hombre. Bol Hosp San Juan de Dios 1980; 27: 24-6.

18.- FLANDERS W D, LALLY C A, ZHU B P, HENLEY S J, THUN M J. Lung cáncer mortality in relation to age, duration of smoking, and daily cigarette consumption: results from Cancer Prevention Study II. Cancer Res 2003; 63: 6556-62.

19. GLANTZ S, BARNES D, BERO L, HANNAUER P, SLADE J. Looking through a keyhole at the tobacco industry. JAMA 1995; 19: 274: 219-24.

20.- BECKER H D. A short history of Bronchoscopy. Cambridge 1987, University Press. www.cambridge.org (Consultado 5.03.2012).

21.- NERUDA P. Estravagario: Laringe, Obras Completas Editorial Losada S. A. Buenos Aires, 1962, pp. 1491-2.

22.- MILLÁN G. "Veneno de escorpión azul". En: Diario de vida y muerte. Ediciones Universidad Diego Portales, Santiago, 2011

23.- ABERLE D R, ADAMS A M, BERG C D, BLACK W C, CLAPP J D, FAGERSTROM R M, et al. Reduced lung-cancer mortality with low-dose computed tomographic screening. N Engl J Med 2011; 365: 395-409.

Correspondencia a:

Dr. Alvaro Undurraga P.

Jefe del Servicio Médico-quirúrgico,

Instituto Nacional del Tórax.

Avda. JM. Infante 717.

Santiago. Chile.

E-mail:alvaroundurragap@yahoo.com 